\title{
Technique for Protecting Chip Corners in Wet Chemical Etching of Silicon Wafers
}

\author{
Wing C. Hui
}

February 1991

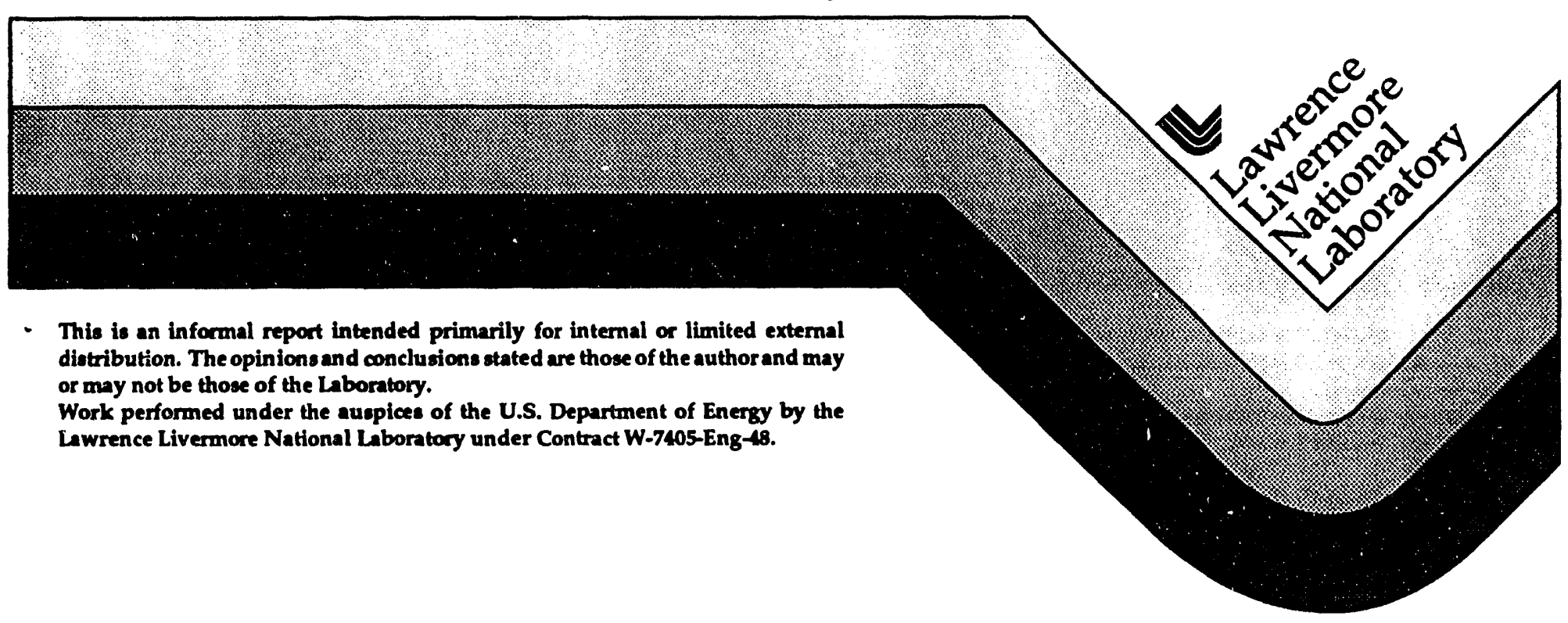




\section{DISCLAIMER}

This document was prepared as an account of work sponsored by an agency of the United States Government. Neither the United States Government nor the University of California nor any of their employees, makes any warranty, express or implied, or assumes any legal liability or responsibility for the accuracy, completeness, or usefulness of any information, apparatus, product, or process disclosed, or represents that its use would not infringe privately owned rights. Reference herein to any specific commercial products, process, or service by trade name, trademark, manufacturer, or otherwise, does not necessarily constitute or imply its endorsement, recommendation, or favoring by the United States Government or the University of California. The views and opinions of authors expressed herein do not necessarily state or reflect those of the United States Government or the University of California, and shall not be used for advertising or product endorsement purposes.

This report has been reproduced

directly from the best available copy.

Available to DOE and DOE contractors from the Office of Scientific and Technical Information

P.O. Box 62, Oak Ridge, TN 37831

Prices a vailable from (615) 576-8401, FTS 626.8401

A vailable to the public from the

National Technical Information Service

US. Department of Commerce

5285 Port Royal Rd.

Springfield, VA 22161 


\title{
TECHNIOUE FOR PROTECTING CHIP CORNERS \\ IN WET CHEMICAL ETCHING \\ OF SILICON WAFERS
}

\author{
Wing C. Hui \\ Lawrence Livermore National Laboratory \\ P.O. Box 808, L-156 \\ Livermore, CA 94550, U.S.A.
}

(415)423-0864

\begin{abstract}
When a silicon wafer is under wet chemical etching, any outer corners of a chip may face severe undercutting. This undercutting problem is extremely serious for the boundary corners of the chips; and very often it can limit the compactness in the design of the chips. A special etching mask pattern was developed for protecting the boundary corners of the chips under wet chemical etching. The main central part of this pattern could prevent any undercutting at the corners during the etching. But, there was a timing "fuse" that would eliminate this central part and open up the corners at any desired time. Thus, the corner protection could be set up for only a specific length of time. With this "timing bomb" device, it in turn could allow better compactness in the design of the chips.
\end{abstract}




\section{(I) INTRODUCTION}

Undercutting is a very common problem in the wet chemical etching of silicon wafers 1 . This problem is almost non-existent at the inner comers of the chip or the device structure, but much more serious at the outer corners.

In the typical anisotropic etching of (100) silicon wafers, the etching patterns are usually bounded by the (111) planes. Any outer comers will then be facing an infinite number of planes, with the sharp corners perpendicular to the (110) planes. Usually, the (111) crystallographic surfaces are the slowest etching planes in silicon, and thus become the etching stops. However, the etching rates on the (110) planes are much faster 2 . Thus the undercutting rate becomes very severe.

Very often, this undercutting problem at the outer corners may highly affect the design of the chips and their compactness. If the outer corner has a lot of space around it, then regular corner compensation technique can be used to eliminate or reduce this problem $3,4,5,6,7$. However, in other cases, such as at the boundaries of the chips, there may not be enough room to do the regular corner compensations. This is especially true when clean and clear scribe lines among the chips are required as the mean for separating the chips.

A special mask pattern had been design for protecting the boundary outer corners of the chips under these circumstances. The main central part of the pattern connected all the 4 corners at the intersection of the scribe lines. It could prevent any undercutting at these corners. In addition to 
the central protection part, there were timing "fuses" attached to it, which would eliminate this central protection part and thus open up the corners at any desired time.

\section{(II) DESIGNING THE PROTECTION DEVICE}

The basic design of the corner protection device is shown in Figure (1). The black and the dark areas are the masks which will protect the silicon surface from etching. Thus the white areas are the ones that will be etched. There are some other versions with slight differences available. They will be discussed later.

Basically, the protection device contained a central protection part and 4 timing "fuses". In order for the readers to understand each feature more clearly, we will show the functions of each feature as in the evolution of the design.

Before we go into the detail of the design, let us review some basic rules or phenomena in the anisotropic etching of (100) silicon wafer. These basic phenomena are shown in Figure (2). First, any boundary parallel to a (111) plane or any right angle inner corner at the perpendicular intersection of (111) planes practically will not be undercut (Figure (2)-(A)). Second, any outer comer will be undercut until it reaches a (111) plane (Figure (2)-(B)). Third, any plane or curve not parallel to (111) plane will be undercut until it 
reaches a (111) plane or a right angle inner comer at (111) planes (Figure (2)-(C)).

The evolution stages of the corner protection device is shown in Figures (3)-(6). A normal anisotropic etching of square chip patterns on a (100) silicon wafer is demonstrated in Figure (3). Figure (3)-(A) shows the outer corners of the chips at the intersection of 2 scribe lines. If there is no corner protection, all these corners will be undercut as indicated in Figure (3)-(B). Usually, the wafers are etched only up to certain point, such as etching through from one side to the other for thin film window fabrication. The longer the etching is the more the undercut will be. If the wafer was left in the long enough and the chip size is small enough, the whole chip pattern can even be eliminated by undercutting.

In order to preserve the original dimensions of these chip patterns, we have to eliminate all the outer comers. Thus we put in a square pad, as the central protection part, to connect all the corners, as shown in Figure (4)(A). Now, there are only inner corners, but no outer one. There will be no undercutting, and the final etched device will be as the one shown in Figure (4)-(B). However, there is one main problem - the scribe lines are not clear through.

Before we show how we can open up the protection, we would like to introduce the timing "fuse" concept first. This concept is shown in Figure (5). (For simplification of the drawings, from now on, all the sliding slopes of the (111) planes will not be shown in the Figures.) If long bars are added to the central protection part (Figure (5)-(A)), there will then be open corners. These bars can be eliminated by undercutting (Figure (5)-(B)), 
until there is no more open corners (Figure (5)-(C)). Eventually, it will just looks like the one with only the central protection part alone. The longer the bars are, the longer time it will take to reach this final state. Thus these bars can be used as the timing "fuses". The timing "fuses" are very important, since we want to decide when to open up the corners later. (The time or "when" in a etching process may be better interpreted as how deep the wafer has been etched.)

Now, we have the central protection part and the timing "fuses". So, it is the time for us to introduce the "bombs" that will "explode" the central protection part. We needs something that will show a sudden big undercutting to eliminate the central protection part only when the timing "fuses" are finished. This is really the key development for the whole design.

One of the ways to build a "bomb" is to put long openings between the "fuses" and the central protection part (Figure (6)-(A)). The undercutting events will be demonstrated step by step from Figure (6)-(B) to Figure (6)$(H)$. As the undercutting of the "fuses" reaches the fronts of these openings (Figure (6)-(B)), new outer corners will be created for further undercutting all the way to the back ends of the openings.

When it reaches the square central part (Figure (6)-(C)), it has open corners in the center of each edges. In contradiction with the one having only the central protection part alone, it now has 8 outer corners for undercutting. The undercutting will progress as shown in Figure (6)-(D).

Eventually, all the linkages between the corners will be eliminated, and an "island" will be left in the center. Now, there are only very slightly undercutting or practically none at each corner of the chips. The actual 
amount will highly depend on the dimensions of the linkages at the corners. Figure ((6)-(E) shows an example of how it should look like.

If desired, the undercutting can be carried on a little bit further to eliminate the island, with a little more undercutting on the corners. Figure (6)-(F) shows how the new structure will look like. Even in such a case, the undercutting of the corners is still much much less than the case without the protection.

The basic pattern can be further modified for some specific purpose. For example, we can put in extra openings at the diagonals of the central pad, as shown in figure (7)-(A). This will guarantee the breakup of the linkages and provide a shorter time for eliminating the central protection part.

If we want to eliminate the island faster and minimize the undercutting at the corners, we can put a opening at the center of the central pad (Figure (7)(B)). Or, we can combine both modifications to have a pattern as shown in Figure (7)-(C). 


\section{(III) EXPERIMENTAL RESULTS}

We had made several wafers to test the real capability of our corner protection technique. These were (100) wafers with samples of our.special protection mask patterns. They were etched anisotropically in $44 \% \mathrm{KOH}$ solution at $75^{\circ} \mathrm{C}$. Silicon nitride was used as the etching mask.

What we had predicted in our designing procedure seemed to occur very accurately. Experimental results on some testing chips showed that the corner protection device was doing everything it was supposed to do. It could protect the corners for a determined period of time and then clear up all the protection linkages at the end.

Figure (8) shows the various stages on one of the sample wafers for the basic pattern design. Except for the original mask (Figure (8)-(A)), the white areas were the original (100) surface. The etched areas were shown in black color. The grey areas were actually the leftovers of the etching mask (silicon nitride) over the etched areas.

Figure (8)-(A) is the picture of the original corner protection mask pattern, with the timing "fuse". Figure (8)-(B) shows when the undercutting reached the fronts of the "bomb" opening and created new outer corners. Figure (8)-(C) was right at the point when the "fuse" was completely gone. Figure (8)-(D) illustrates further undercutting at the central protection part. Figure (8)-(E) shows the final look when all the protection linkages were cleared and only a small central "island" was left. Figure (8)-(F) demonstrates the slightly extra undercutting for eliminating the central "island" completely. 
For comparison purpose, Figure (9) shows some $2 \mathrm{~mm} \times 2 \mathrm{~mm}$ chips with and without the corner protection devices. The wafers were etched 138 microns ( $0.138 \mathrm{~mm}$ or $\left.0.00543^{\prime \prime}\right)$ deep. Figure (9)-(A) shows the chips with the corner protection devices after etching. It was at the stage

that the central islands had been eliminated. The corners seemed to be barely undercut. If the etching was stopped at the stage with the island had just been formed, the undercutting at the corners would even be less. In other words, the corners would even be much sharper. In contrast, Figure (9)-(B) shows the chips without the protection devices. Undercutting was able to eroding the comers of the chips.

If the wafer was etched deeper, the erosion would be much worse. For example, Figure (10) shows a photography of a 0.008 " thick wafer with $2 \mathrm{~mm} \times 2 \mathrm{~mm}$ chips with rectangular silicon nitride thin film window. The central window parts were etched completely through, i.e. 0.008 ".

Obviously, the corners were undercut badly.

If the thin film windows were made with standard 0.012 " thick 2-inch wafers or $0.015 "$ thick 3 -inch wafers, the corners would be rounded off much more. In addition, if the chip size was smaller, such as $1 \mathrm{~mm} \mathrm{X} 1 \mathrm{~mm}$ or $0.5 \mathrm{~mm} \times 0.5 \mathrm{~mm}$, the undercutting would really chop off a large portion of the chip design. 


\section{(IV) CONCLUSION}

Original anisotropic etching technique will erode the corners of the chips on (100) silicon wafer by undercutting. The deeper the etching is the more the corners will be rounded off. However, we have developed a technique to counter this problem. With our specially designed comer protection mask pattern, the original outer geometry of the chip design can be preserved. This, in turn, will allow higher compactness in the future chip designs; at the same time, the outer geometry can now be controlled to meet the chip application requirements. 


\section{(VI) REFERENCES}

1. K.E. Petersen, Silicon as a mechanical material, Proceedings of the IEEE, 70 (1982), pp. 420-457.

2. J.B. Price, Anisotropic etching of silicon with $\mathrm{KOH}-\mathrm{H}_{2} \mathrm{O}$-isopropyl alcohol, Semiconductor Silicon 1973, The Electrochemical Society, Inc., edited by H.R. Huff \& R.R. Burgess, pp.339-353.

3. X. Wu, Q. Wu, \& W. Ko, A study on deep etching of silicon using EPW, Transducers of 1985 International Conference on Solid-State Sensors and Actuators, (1985), pp. 291-294.

4. D.R. Ciarlo, Corner compensation structures for (110) oriented silicon, Proceedings of IEEE Micro Robots and Teleoperators Workshop, (1987).

5. S. Chang, \& D. Hicks, Mesa structure formation using potassium hydroxide and ethylene diamine based etchants, Technical Digest of IEEE Solid-State Sensor and Actuators Workshop , (1988), pp.102103.

6. X. Wu, \& W. Ko, Compensating corner undercutting in anisotropic etching of (100) silicon, Sensors and Actuators, 18 (1989), pp. 207215.

7. G. Mayer, H. Offereins, H. Sandmaier, \& K. Kuhl, Fabrication of nonunderetched convex corners in anisotropic etching of (100)-silicon in aqueous $\mathrm{KOH}$ with respect to novel micromechanic elements, J. Electrochem. Soc., 137 (1990), pp. 3947-3951. 


\section{EIGURE CAPTIONS}

Figure (1): An example of the basic design for the corner protection device.

Figure (2): The basic phenomena in the anisotropic etching of (100) silicon wafer. (A) Boundaries parallel to (111) planes and right angle inner corners at (111) plane intersections of (111) planes will not be indercut. (B) Outer corner will be undercut until it reaches a (111) plane. (C) Plane anes curve not parallel to (111) plane will be undercut until they reaches a (111)plane or an inner corner at (111) planes.

Figure (3): Normal anisotropic etching of square chip patterns on a (100) silicon wafer. (A) Before etching. (B) After etching.

Figure (4): Anisotropic etching of square chip patterns on a (100) silicon wafer with square protection pads connecting all the corners. (A) Before etching. (B) After etching.

Figure (5): Anisotropic etching of square chip patterns on a (100) silicon wafer with square protection pad and timing "fuses". (A) Before etching. (B) Undercutting of the "fuse" bars during etching. (C) "Fuse" bars eliminated completely by undercutting.

Figure (6): Anisotropic etching of square chip patterns on a (100) silicon wafer with the basic corner protection device. (A) Before etching. (B) Undercutting of "fuses" reaches the front ends of the openings. (C) Undercutting reaches the central protection 
pad. (D) Undercutting starts to eliminate the central protection pad. (E) Undercutting has eliminated all the linkages and leaves an central "island". (F) Further undercutting has eliminated the central "island".

Figure (7): Modified forms of the corner protection devices. (A) With diagonal openings to help breaking the linkages. (B) With central opening to help eliminating the "island". (C) With both diagonal openings and central opening.

Figure (8): Experimental results of the anisotropic etching of square chip patterns on a (100) silicon wafer with the basic corner protection device. (Black $=$ etched area, white $=$ unetched area, and grey $=$ left over SiN above etched area.) (A) Before etching. (B) Undercutting of "fuses" reached the front ends of the openings. (C) Undercutting reached the central protection pad. (D) Undercutting started to eliminate the central protection pad. (E) Undercutting had eliminated all the linkages and leaves an central "island". (F) Further undercutting had eliminated the central "island".

Figure (9): (A) The $2 \mathrm{~mm} \times 2 \mathrm{~mm}$ chips with the comer protection devices after being etched 138 microns $(0.00543 ")$ deep. The central islands were eliminated. (B) The $2 \mathrm{~mm} \times 2 \mathrm{~mm}$ chips without the corner protection devices after being etched 138 microns (0.00543") deep.

Figure (10): The $2 \mathrm{~mm} \mathrm{X} 2 \mathrm{~mm}$ silicon nitride window chips on a 0.008 " thick wafer after being etched all the way through without the corner protection devices. 


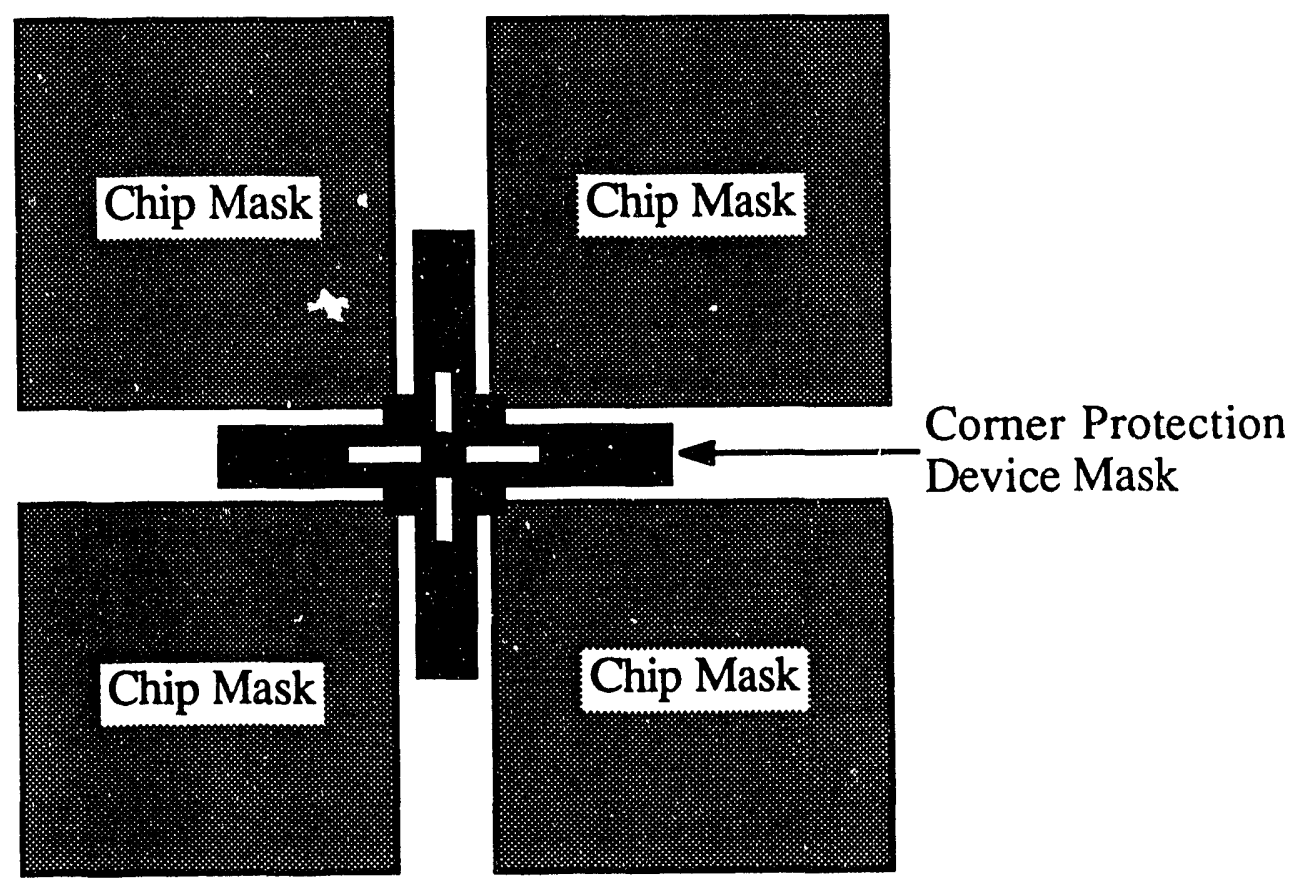

Figure (1) 


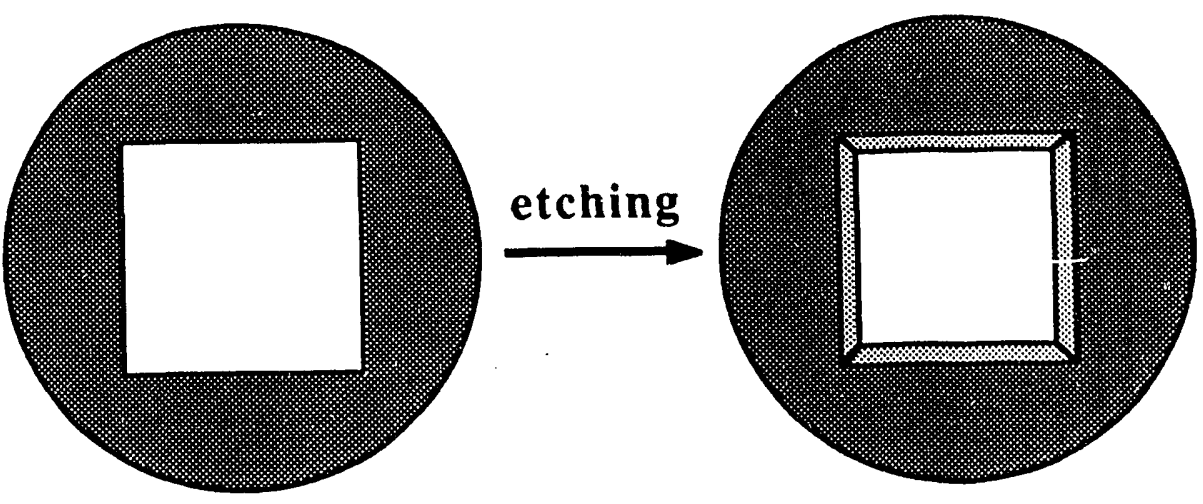

(A)
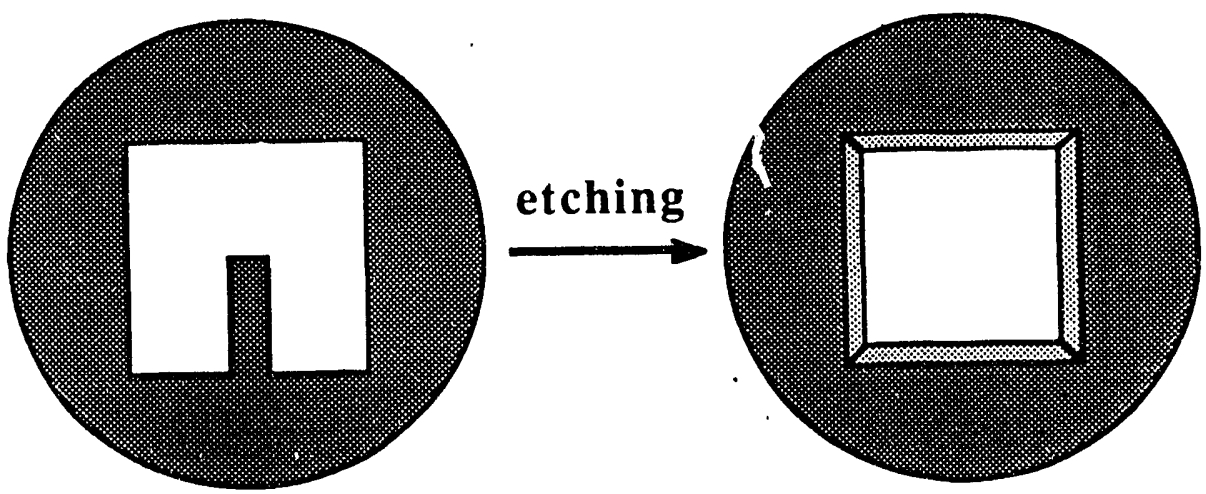

(B)
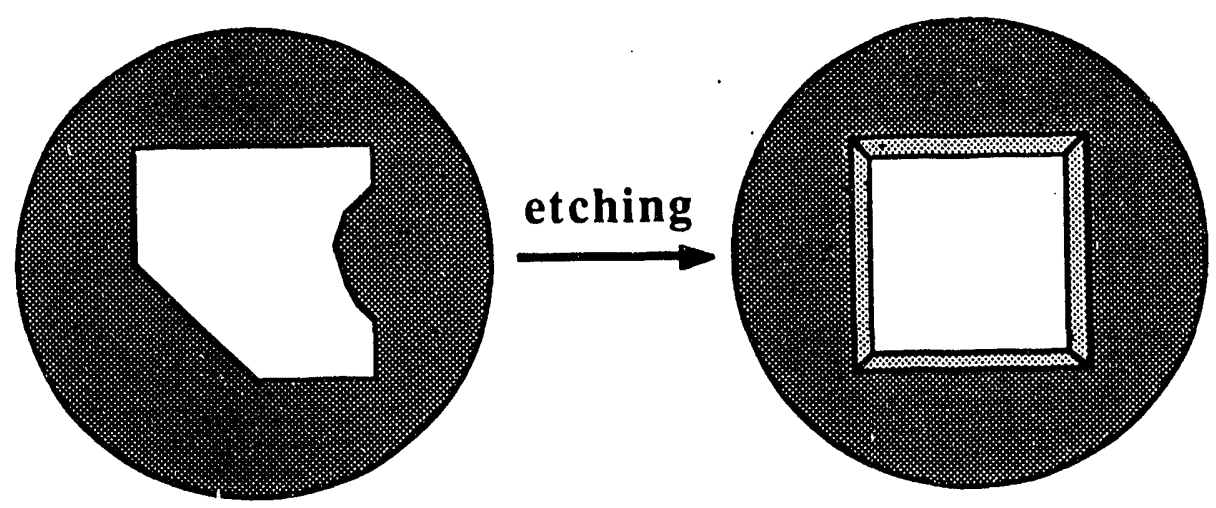

(C)

Figure (2) 

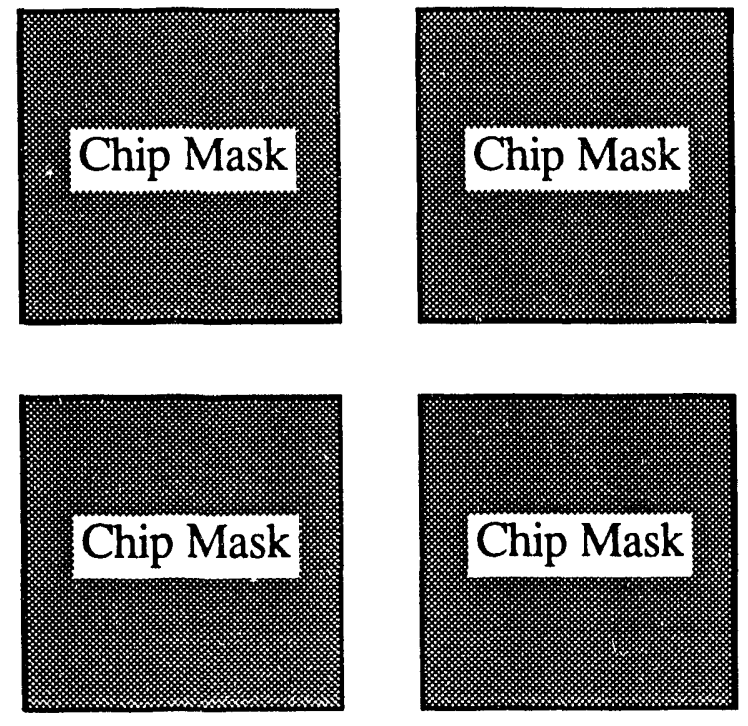

(A)

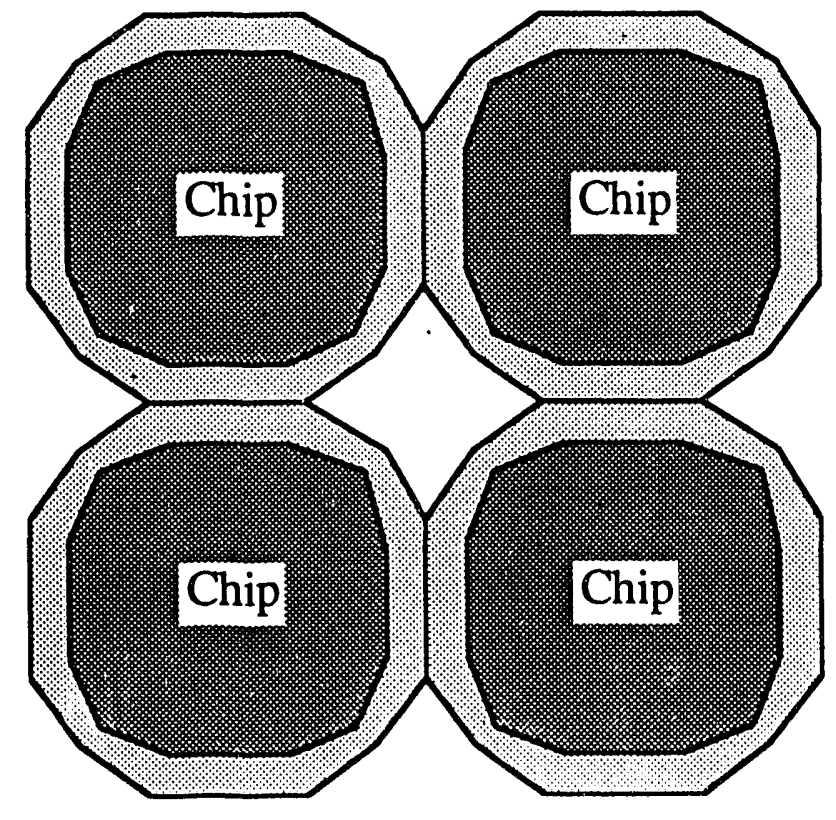

(B)

Figure (3)

-14 - 


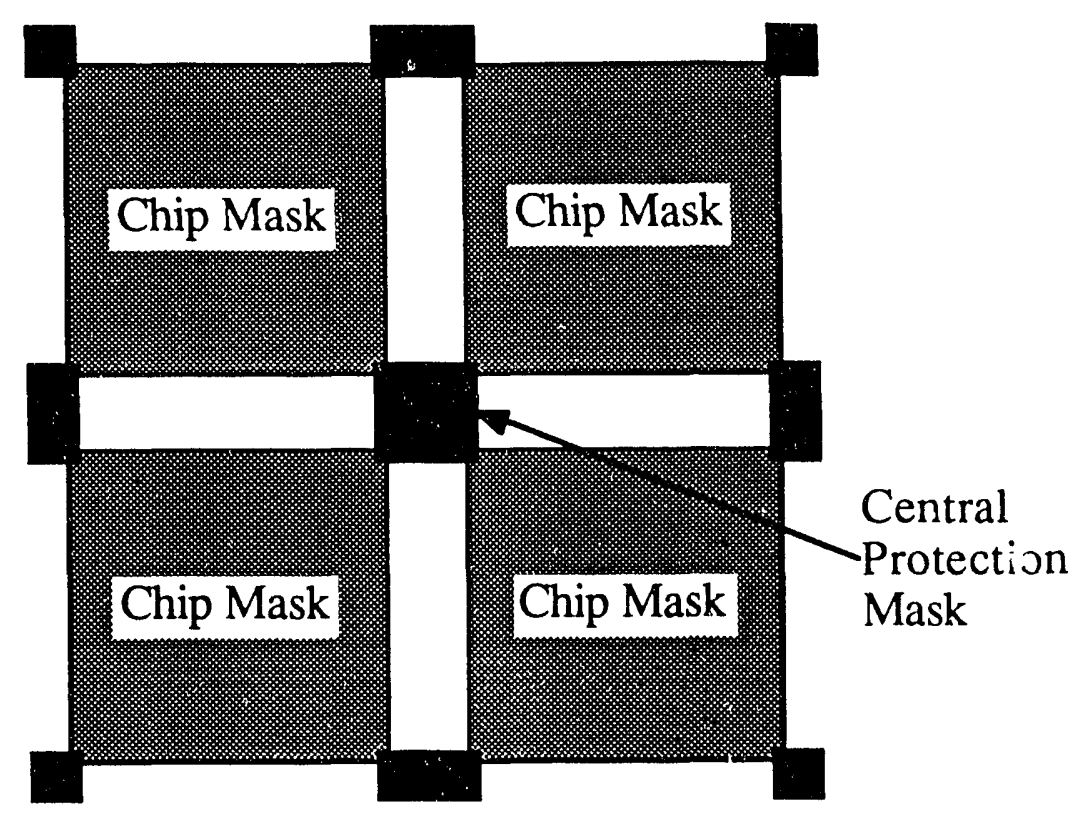

(A)

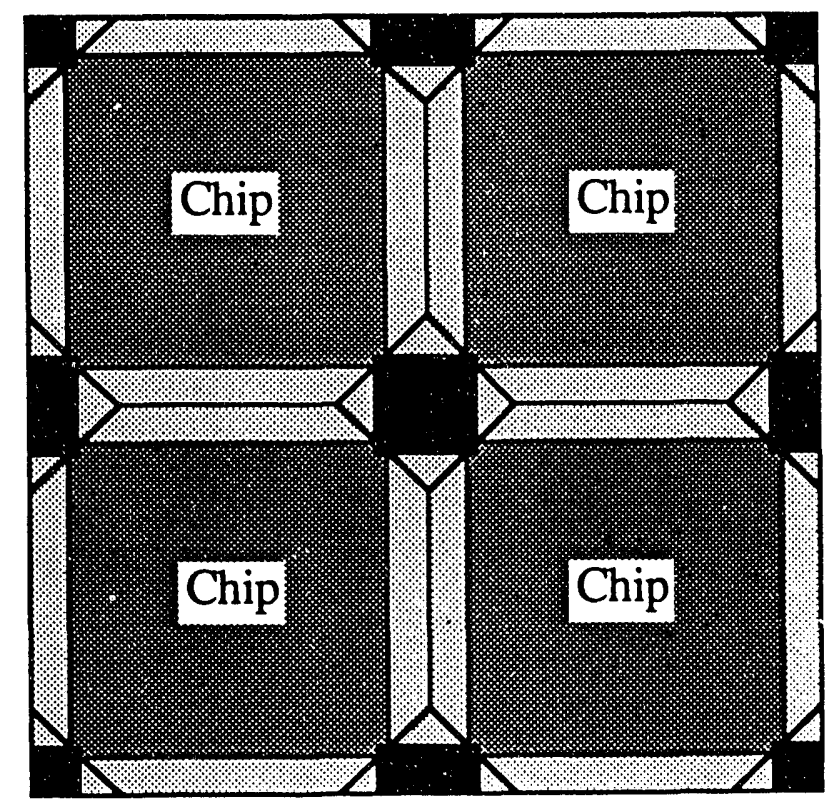

(B)

Figure (4) 


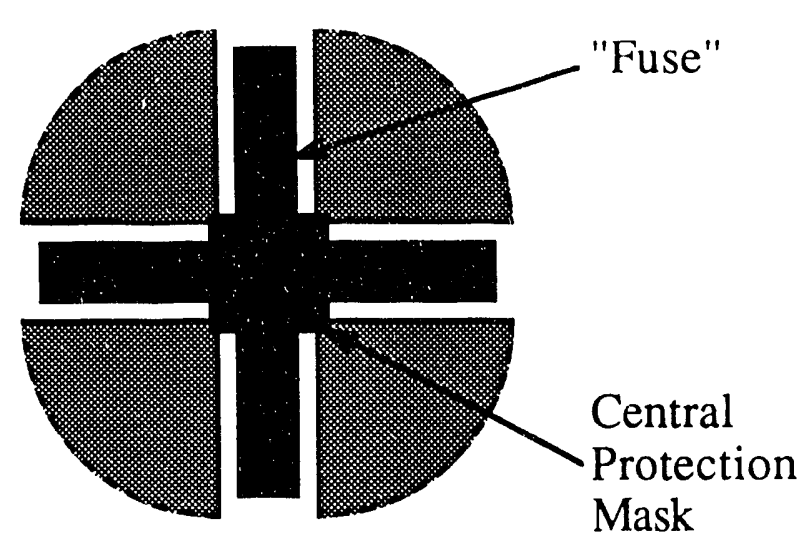

(A)

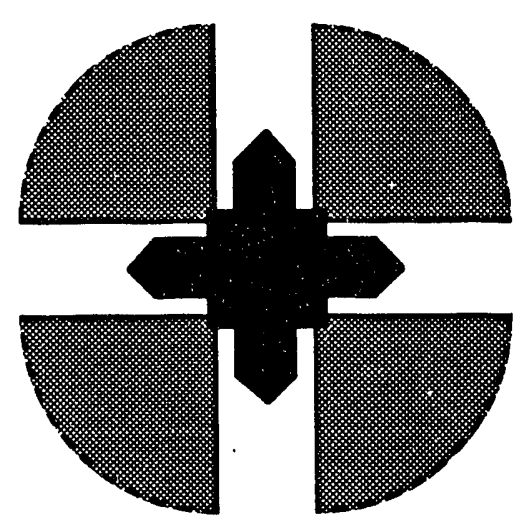

(B)

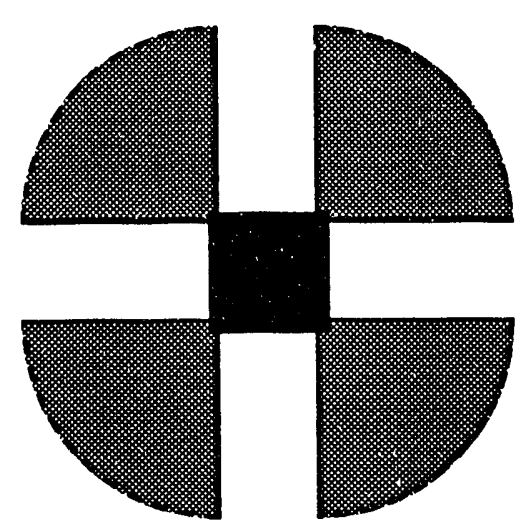

(C)

Figure (5)

$-16-$ 


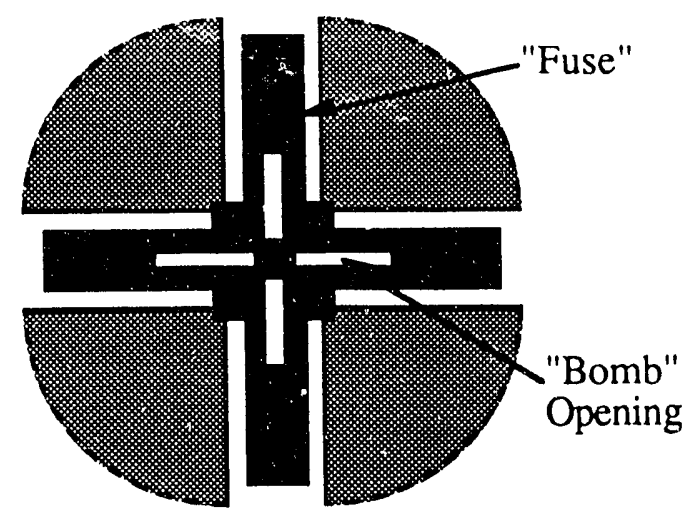

(A)

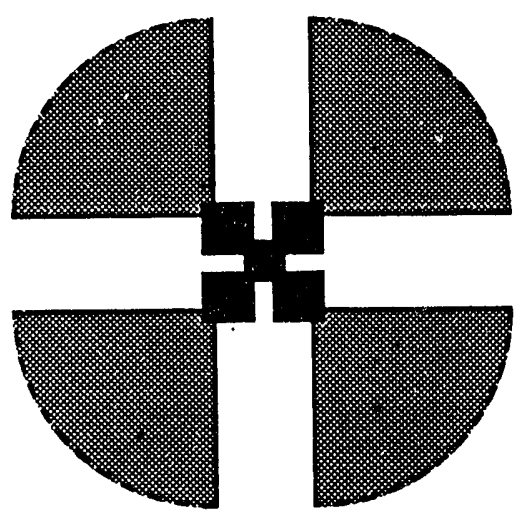

(C)
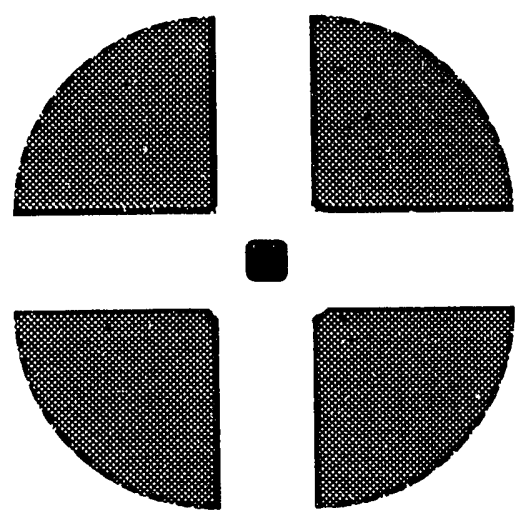

(E)

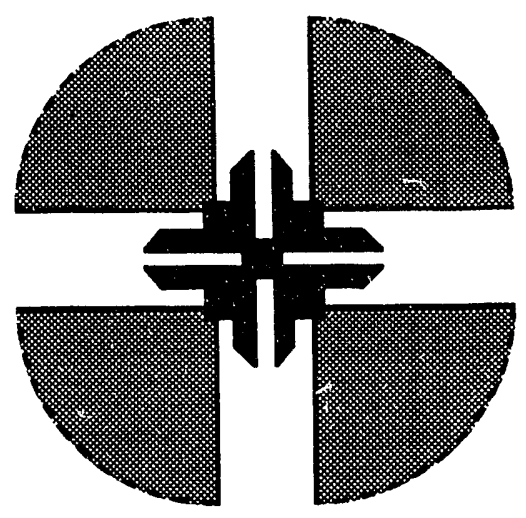

(B)

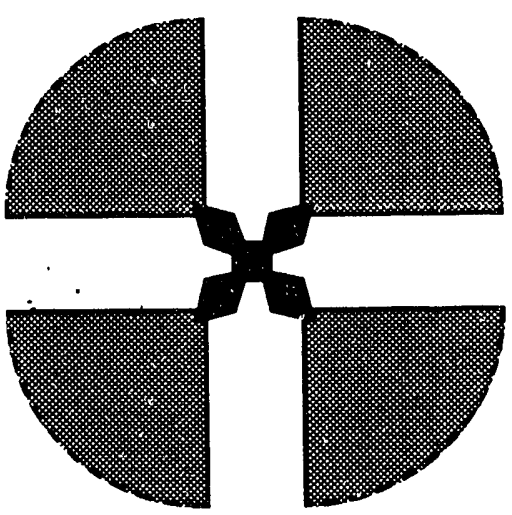

(D)
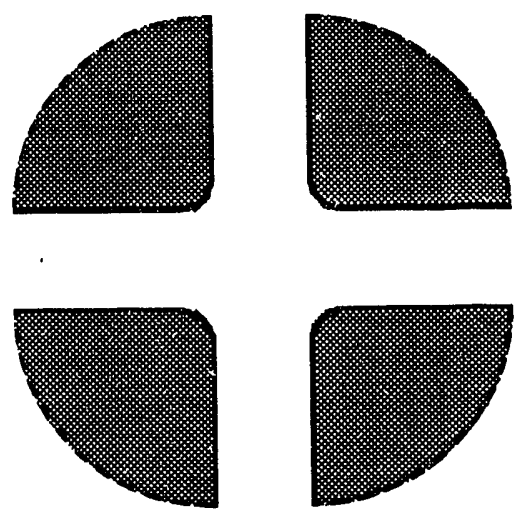

(F)

Figure (6) 


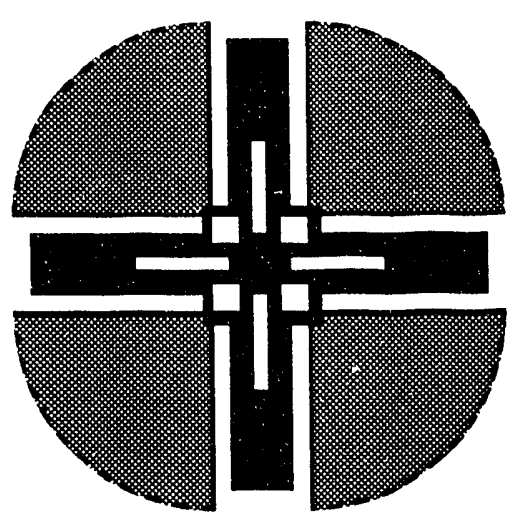

(A)

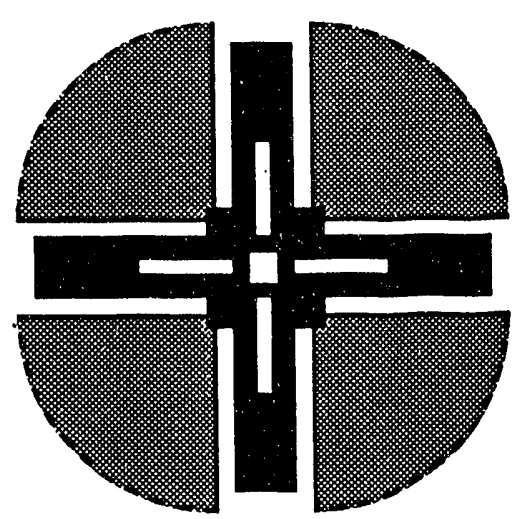

(B)

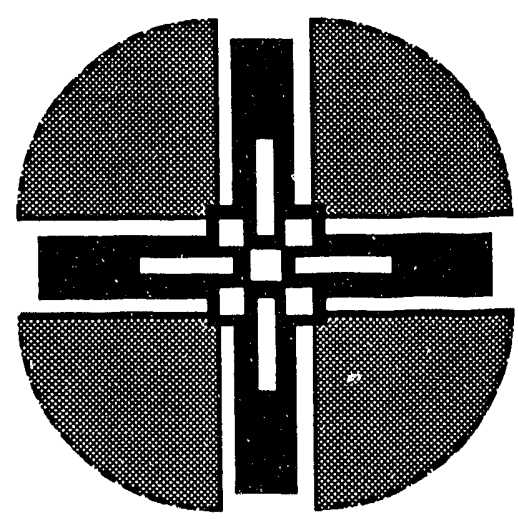

(C)

Figure (7)

$-18-$ 

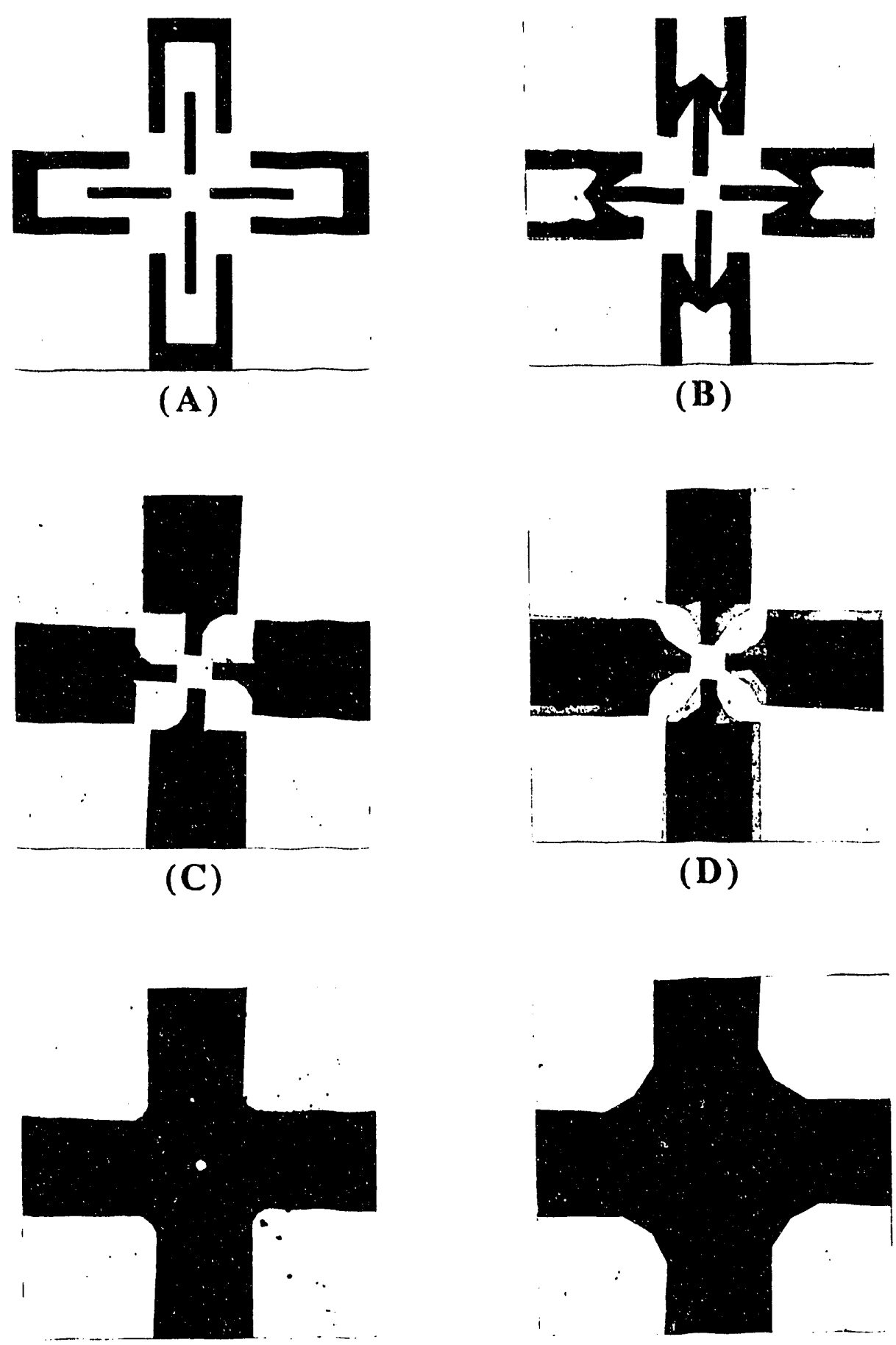

(E)

(F)

Figure (8) 


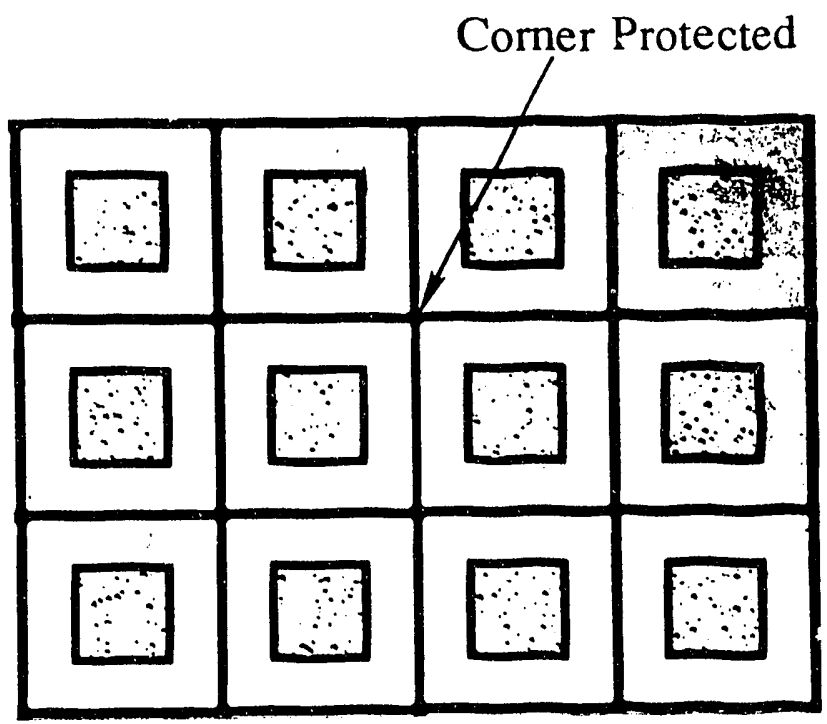

(A)

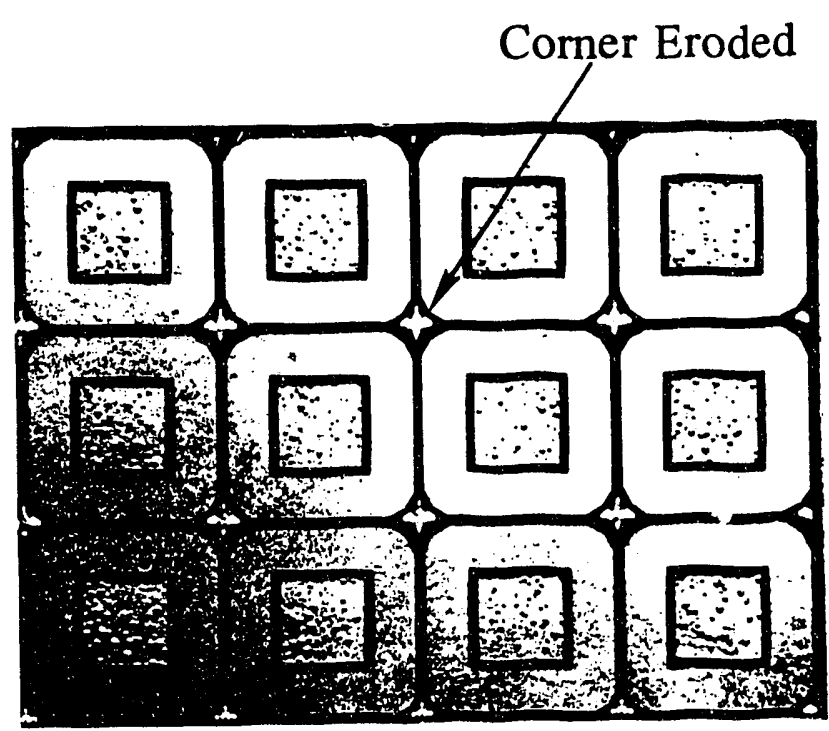

(B)

Figure (9) 


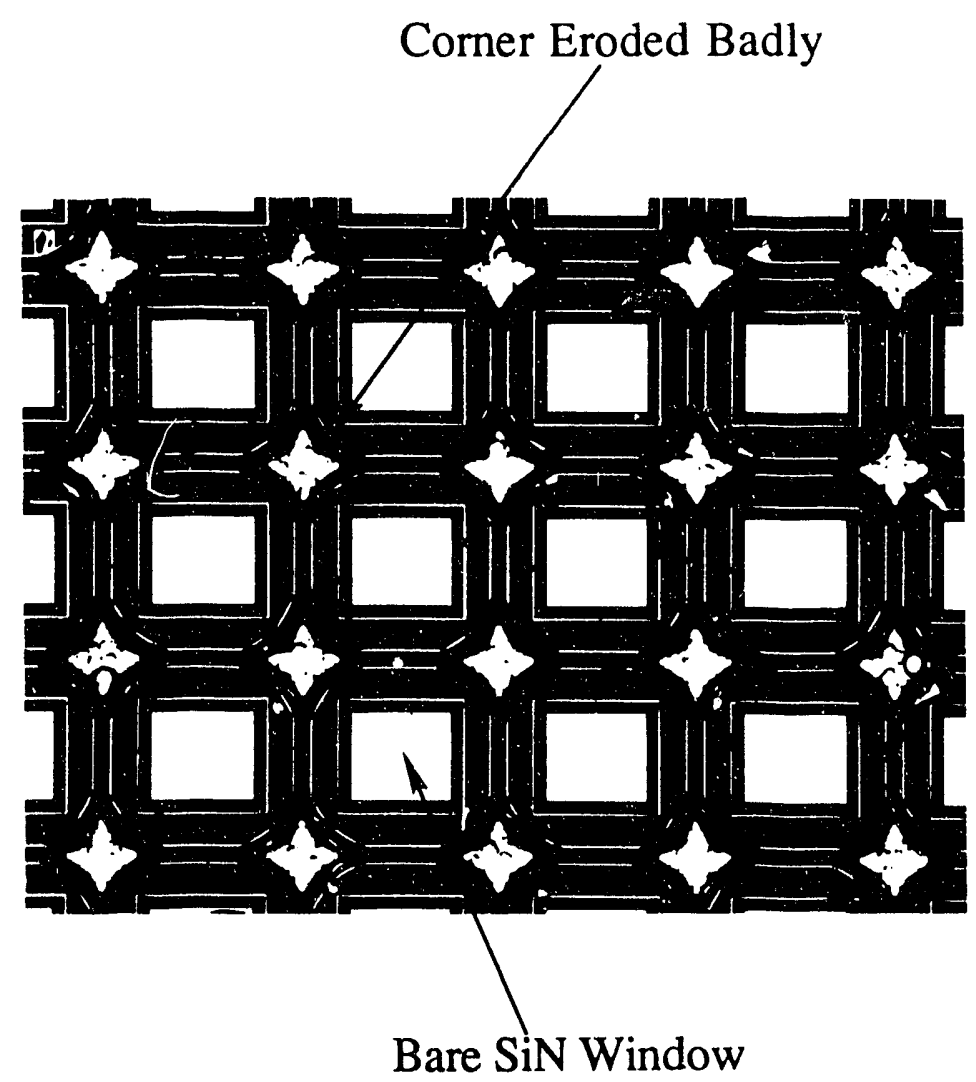

Figure (10) 


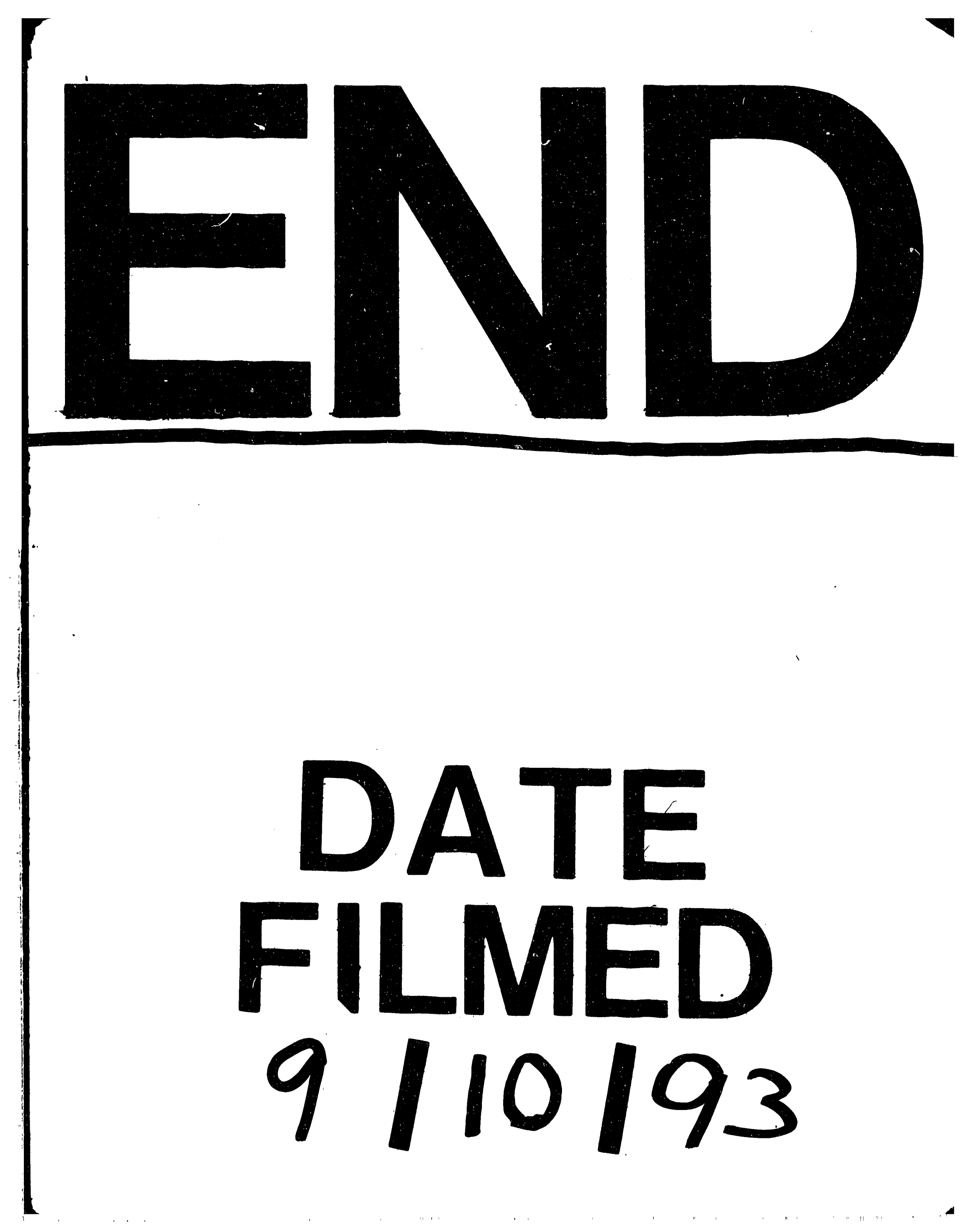

